九州大学学術情報リポジトリ

Kyushu University Institutional Repository

Seasonal Fluctuations of Populations and Effects of Temperatures on Development and Growth in the Tick, Haemaphysalis flava

Kakuda, Hiroyuki

Zoological Laboratory, Faculty of Agriculture, Kyushu University

Shiraishi, Satoshi

Zoological Laboratory, Faculty of Agriculture, Kyushu University

Uchida, Teruaki

Zoological Laboratory, Faculty of Agriculture, Kyushu University

https://doi.org/10.5109/23945

出版情報: 九州大学大学院農学研究院紀要. 35 (1/2)，pp.17-26，1990-12. Kyushu University バージョン：

権利関係 : 


\title{
Seasonal Fluctuations of Populations and Effects of Temperatures on Development and Growth in the Tick, Haemaphysalis flava
}

\author{
Hiroyuki Kakuda, Satoshi Shiraishi* and Teru Aki Uchida \\ Zoological Laboratory, Faculty of Agriculture, \\ Kyushu University 46-06, Fukuoka 812, Japan \\ (Received May 15, 1990)
}

\begin{abstract}
As a part of ecological studies on Haemaphysalis flava, the seasonal fluctuations of tick populations in the vicinity of Fukuoka City were investigated, and the species and the number of ticks on hares were checked in winter. Moreover, the effects of temperatures on development and growth in H. flava were analysed.

In the woodland, H. flava was found on vegetation throughout the year, but in the grassland no ticks were found in summer. H. longicomis disappeared from vegetation during the November-February period of hibernation. H. flava was dominant on the hares captured in winter. In H. flava, oviposition, hatching and moulting did not occur at temperatures of $15 \%$ and below, and the developmental zero was $12.3^{\circ} \mathrm{C}$. The critical low temperatures for moulting of larvae and nymphs were 14.5 and $17.0^{\circ} \mathrm{C}$, respectively. High temperatures exerted a harmful influence upon oviposition and hatching. The temperature required for $H$. flava to be active was lower than that for H.longicormis, but the lowest temperature for development and growth in H. flava was higher than in H. longicomis, and the upper limiting temperature in the former tick was lower than in the latter : thus, it was revealed that $H$. flava develops and grows within a narrower range of temperatures than does H.longicomis.
\end{abstract}

\section{INTRODUCTION}

Haemaphysalis flava is widely distributed in Japan and parasitises various kinds of mammals and birds. In the Kyushu district, the tick has been collected from such species of medium- and large-sized mammals as the Japanese hare, Japanese raccoon dog, dogs, the Tsushima yellow marten, Korean weasel, horses, the Japanese wild hog and cattle (Yamaguti et al., 1971; Kakuda et al., 1989). Notwithstanding its broad distribution, there have been only a few ecological studies on this tick in Niigata Prefecture (Saito, 1959), Chiba Pref. (Asanuma and Sakurai, 1958) and Saitama Pref. (Fujimoto et al., 1986, 1987 ; Fujimoto and Yamaguti, 1987a).

On the other hand, H. flava is known as a vector for tularemia (Asanuma et al., 1956 ; Asanuma and Sakurai, 1958 ; Fujita et al., 1985). Recently, epidemiology on such tick-borne diseases as Lyme disease (Kawabata et al., 1987 ; Hashimoto et al., 1989 ; Honma, 1989 ; Miyamoto et al., 1990) and Japanese spotted fever (Mahara, 1987 ; Takada et al., 1988 ; Mahara and Fujita, 1989) has been regarded as important in Japan. However, there have been few ecological studies, except for the cattle tick, Haemaphysalis Iongicomis, a known vector for theileriosis caused by Theileria sergenti (Namba, 1958 ; Yoshida, 1975, 1980 ; Chikaki, 1976 ; Shiraishi et al., 1982, 1989 ; Ito et

* To whom reprint requests should be addressed. 
al., 1983, etc. ). Therefore, the aim of the present study is to elucidate the life history of $H$. flava by field observations, to clarify the effects of temperatures on development and growth by laboratory experiments, and to discuss the physiological and ecological nature of this tick in comparison with that of $H$. Zongicoynis.

\section{MATERIALS AND METHODS}

Seasonal fluctuations of tick populations : The field investigation was conducted in Kasuya Forest of Kyushu University, Fukuoka Prefecture during the period from June 1987 to May 1988. One study area (grassland) was a pasture dominated by the bahiagrass, Paspalum notatum (altitude ca. $60 \mathrm{~m}$ ) and grazing did not take place throughout this period. Another area (woodland at the same altitude as the pasture) was a mixed forest consisting of the Japanese red pine, Pinus densiflora and broadleaved trees. The forest was shaded even in the daytime and its floor was densely covered with weeds. In both study areas, ticks were collected by the drag method with a flannel $(1 \times 1 \mathrm{~m})$ in each habitat $\left(\mathrm{ca} .200 \mathrm{~m}^{2}\right)$ once a month at $10: 00-12: \mathbf{0 0}$. All the attached ticks on the flannel were counted.

Ticks from hares in winter : Ticks on five Japanese hares, Lepus brachyurus brachyurus captured in Kasuya District, Fukuoka Pref. from December 1988 to January 1989 were removed upon visual inspection.

Effects of temperatures on development and growth in $H$. flava: Unfed nymphs and adults collected by the drag methods, and laboratory-hatched larvae were fed on the rabbits to complete engorgement and detachment. The detached ticks, including all the stages, were placed in Petri dishes (diam. $6 \mathrm{~cm}$ ) whose bottoms were covered with wet filter papers (ca. $100 \% \mathrm{RH}$ ), and reared in dark incubators maintained at five constant temperatures $\left(10,15,20,25\right.$ and $\left.30^{\circ} \mathrm{C}\right)$. The premoulting periods and moulting ratios of detached larvae and nymphs, and the preoviposition and oviposition periods and the number of eggs deposited per $\mathrm{mg}$ of body weight of detached females were examined. The incubation period and hatching ratio for eggs gathered from egg batches deposited by females placed at $25^{\circ} \mathrm{C}$ were analysed at seven different temperatures $\left(10,15,20,25,27,29\right.$, and $\left.30^{\circ} \mathrm{C}\right)$.

\section{RESULTS}

Seasonal fluctuations of populations in two Haemaphysalis species in grassland and woodland

Only two species, H. flava and H. longicornis were collected in both study areas ; thus, seasonal fluctuations of their populations were separately described according to the species (Figs. 1 and 2).

\section{1) H. flava}

Fig. $1 \mathrm{~A}$ and $1 \mathrm{~B}$ indicate the seasonal fluctuations of $H$. flava populations in the grassland and woodland, respectively. No larva was collected in the grassland. In the woodland, however, a great number of larvae were found from August to October 
with a peak in August. The active period of nymphs in both study areas extended from autumn of 1987 to the next spring with few nymphs in summer. The nymphs in the grassland and woodland had similar bimodal fluctuations with two peaks in November and March, although those in the latter were more abundant than in the former. The adults showed a similar fluctuation pattern to the nymphal pattern in the grassland, whereas a very small number of adults were collected in the woodland without a bimodal fluctuation.
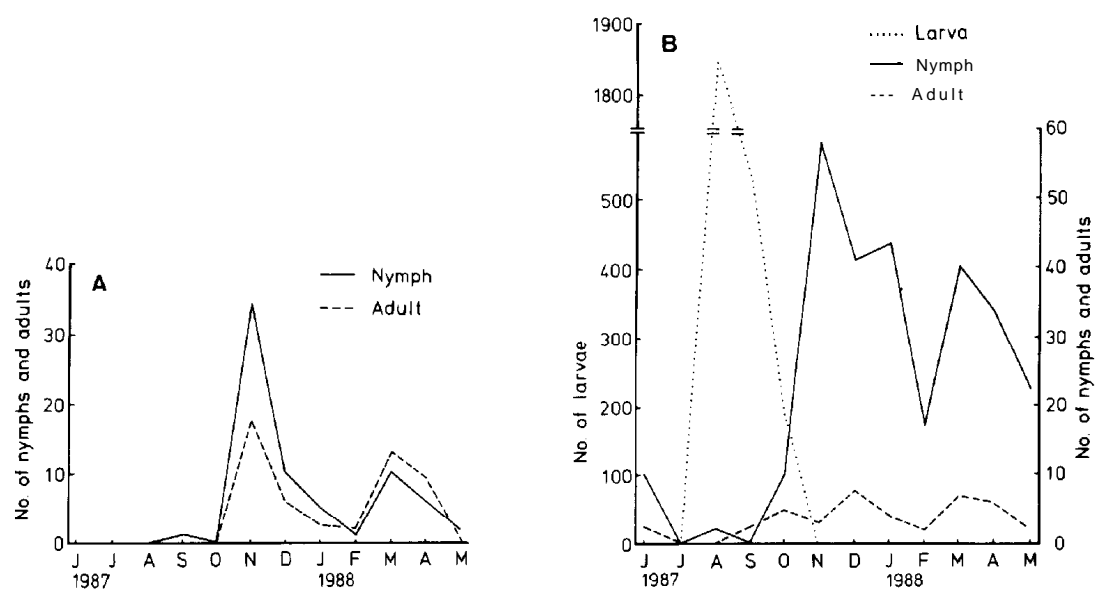

Fig. 1. Seasonal fluctuations of Haemaphysalis flava populations in the grassland (A) and woodland (R) in Kasuya Forest of Kyushu University, Fukuoka Prefecture, from June 1987 to May 1988. Note the absence of larvae in the grassland during the summer.

\section{2) H . longicornis}

The seasonal fluctuations of $H$. longicomis in the grassland and woodland are shown in Fig. 2A and 2B, respectively. Although the larvae were more abundant in the grassland than in the woodland, in both study areas their fluctuations had a unimodal pattern with a peak in September. In both areas, a large number of nymphs were collected in spring with a maximum in April ; a considerably high incidence was recognized also in June, but in the woodland there was no peak in September seen in the grassland. In both areas, the total number of adults was much smaller than that of the immatures, with a few adults in summer. Every developmental stage of $H$. longicornis disappeared from vegetation during the winter from November to February.

\section{Ticks from hares in winter}

A total of 2,043 ticks, consisting of $H$. flava, $H$. kitaokai, Ixodes ovatus and $I$. nipponensis, were collected from five Japanese hares captured during the hunting season (Table 1). H. flava was most abundant in number (1,952), occupying $95.5 \%$ of all collected ticks : according to the developmental stages, the adults $(1,088$ o 5 , en bloc) were most abundant $(55.7 \%)$, the nymphs were next abundant $(39.1 \%)$ and the larvae were least $(5.2 \%)$. Other ticks were much smaller in number than $H$. flava, 
i. e. H. kitaokai, 1 ; I. ovatus, 9 and I. nipponensis, 81 , all of which consisted of adults.
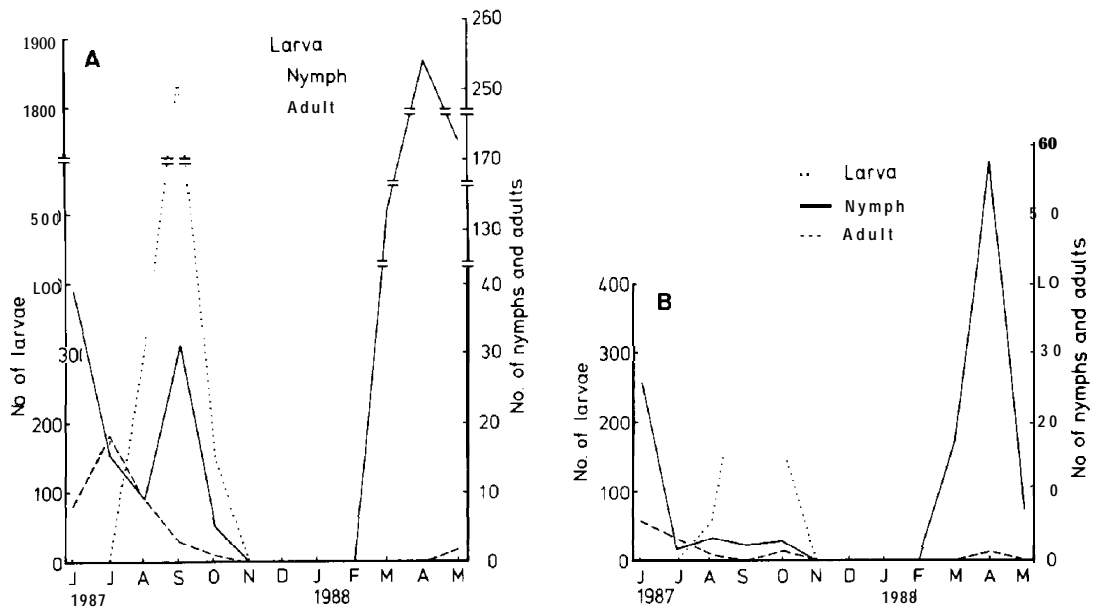

Fig. 2. Seasonal fluctuations of Haemaphysalislongicomis populations in the grassland (A) and woodland (B) in Kasuya Forest of Kyushu University, Fukuoka Prefecture, from June 1987 to May 1988. Note the absence of the tick during the winter in both the grassland and the woodland, which contrasts conspicuously with the fluctuation pattern of $H$. flava in Fig. 1.

Table 1. Ticks on five Japanese hares, Lepus brachyurus brachyurus captured in Kasuya District, Fukuoka Prefecture from December 1988 to January 1989.

\begin{tabular}{lrrrrr}
\hline & \multicolumn{3}{c}{ Developmental stage } & Total \\
\cline { 2 - 4 } Tick species & $\mathrm{L}$ & $\mathrm{N}$ & \multicolumn{1}{c}{ T } & 早 & \\
Haemaphysalis flava & 101 & 763 & 897 & 191 & 1,952 \\
H. kitaokai & 0 & 0 & 1 & 0 & 1 \\
Ixodes ovatus & 0 & 0 & 2 & 7 & 9 \\
I. nipponensis & 0 & 0 & 37 & 44 & 81 \\
\hline
\end{tabular}

L, larva ; N, nymph.; $\sigma^{7}$, adult male ; + , adult female.

Effects of temperatures on development and growth in $\boldsymbol{H}$. flava

1) Oviposition

As shown in Table 2, all females did not oviposit even 3 months after detachment at $10^{\circ} \mathrm{C}$ and $15^{\circ} \mathrm{C}$. The preoviposition period was shortened from a mean of 26.0 days to 8.5 days as the temperatures rose from $20^{\circ} \mathrm{C}$ to $25^{\circ} \mathrm{C}$, but it became longer $(11.0$ days) at $30^{\circ} \mathrm{C}$ than at $25^{\circ} \mathrm{C}$. Thus, the critical low temperature for oviposition could not be calculated. The oviposition period was longest at $20^{\circ} \mathrm{C}(27 . \mathrm{O}$ days on an 
average) and was 9.5 days at both $25^{\circ} \mathrm{C}$ and $30^{\circ} \mathrm{C}$. The number of eggs deposited per mg of body weight was most abundant at $20^{\circ} \mathrm{C}(9.2)$ and was 6.7 at $25^{\circ} \mathrm{C}$ and $30^{\circ} \mathrm{C}$.

Table 2. Oviposition ability at constant temperatures and $100 \% \mathrm{RH}$ in detached females* of Haemaphysalis flava.

\begin{tabular}{|c|c|c|c|c|}
\hline \multicolumn{5}{|c|}{ Temperature $\left({ }^{\circ} \mathrm{C}\right)$} \\
\hline \multirow[t]{4}{*}{10} & 15 & 20 & 25 & 30 \\
\hline & & $26.0 \pm 11.63$ & $8.5 \pm 0.58$ & $11.0 \pm 4.83$ \\
\hline & & $27.0 \mathrm{i} 4.55$ & $9.5 \pm 5.32$ & $9.5 \mathrm{t} 1.29$ \\
\hline & & $9.2 \pm 0.70$ & $6.7 \mathrm{k} 2.11$ & $6.7 \mathrm{k} 1.53$ \\
\hline
\end{tabular}

Preoviposition

period

(days)

Oviposition

period

(days)

No. of eggs

deposited/mg

body weight

A symbol of - shows no oviposition even after 3 months.

Values are $\mathrm{M} \pm \mathrm{S}$. D.

*The number of females used is 4 specimens for each temperature.

\section{2) Egg hatching}

As given in Table 3, the incubation period was shortened as the temperatures became higher. However, no egg hatched even 3 months after deposition at the temperatures of $10^{\circ} \mathrm{C}$ and $15^{\circ} \mathrm{C}$, and all eggs died at $30^{\circ} \mathrm{C}$. The hatching ratio decreased with increased temperatures, being highest at $20^{\circ} \mathrm{C}(96.6 \%)$. The developmental zero was $12.3^{\circ} \mathrm{C}$, which was theoretically calculated from a regression line $(\mathrm{Y}=$ $-0.029+0.0023 \mathrm{X}, \mathrm{r}=\mathrm{O} .97)$ of the inverse of the incubation periods $\mathrm{Y}$ on the temperatures $\mathrm{X}\left(20,25,27\right.$ and $\left.29^{\circ} \mathrm{C}\right)$.

Table 3. Incubation period and hatching ratio at constant temperatures and $100 \% \mathrm{RH}$ in Haemaphysalis flava.

\begin{tabular}{|c|c|c|c|c|c|c|c|}
\hline & \multicolumn{7}{|c|}{ Temperature $\left({ }^{\circ} \mathrm{C}\right)$} \\
\hline & 10 & 15 & 20 & 25 & 27 & 29 & 30 \\
\hline $\begin{array}{l}\text { No. of eggs } \\
\text { examined }\end{array}$ & 200 & 200 & 640 & 805 & 532 & 300 & 735 \\
\hline $\begin{array}{l}\text { Incubation } \\
\text { period } \\
\text { (days)* }\end{array}$ & & & $53.6 \mathrm{zk} 6.96$ & $37.8 \mathrm{i} 1.96$ & $27.7 \mathrm{i} 2.71$ & $25.8 \mathrm{t} 4.72$ & \\
\hline $\begin{array}{l}\text { Hatching } \\
\text { ratio(\%) }\end{array}$ & $\begin{array}{c}0 \\
(0)\end{array}$ & $\begin{array}{c}0 \\
(0)\end{array}$ & $\begin{array}{c}96.6 \\
(618)\end{array}$ & $\begin{array}{c}89.4 \\
(720)\end{array}$ & $\begin{array}{c}76.7 \\
(408)\end{array}$ & $\begin{array}{c}50.3 \\
(151)\end{array}$ & $\begin{array}{c}0 \\
(0)\end{array}$ \\
\hline
\end{tabular}


3) Moulting

The premoulting periods and moulting ratios of the detached larvae and nymphs are shown in Table 4. The higher the temperatures, the shorter the premoulting periods of both stages, and the premoulting period took longer time in the nymphs than in the larvae at each temperature. At $10^{\circ} \mathrm{C}$ and $15^{\circ} \mathrm{C}$, however, moulting did not occur in both stages even 3 months after detachment. High moulting ratios were recorded in both larvae and nymphs at 20,25 and $30^{\circ} \mathrm{C}$. The critical low temperature for larval moulting was $14.5^{\circ} \mathrm{C}$, which was calculated from a regression line ( $\mathrm{Y}=-0.083+$ $0.0057 \mathrm{X}, \mathrm{r}=0.77)$ of the inverse of the premoulting periods $\mathrm{Y}$ on the temperatures $\mathrm{X}$ $\left(20,25\right.$ and $\left.30^{\circ} \mathrm{C}\right)$. As for nymphal moulting, it was $17.0^{\circ} \mathrm{C}(\mathrm{Y}=-0.083+0.0049 \mathrm{X}, \mathrm{r}=$ $0.87)$.

Table 4. Premoulting period and moulting ratio at constant temperatures and $100 \% \mathrm{RH}$ in detached larvae and nymphs of Haemaphysalis flava.

\begin{tabular}{|c|c|c|c|c|c|c|}
\hline & & \multicolumn{5}{|c|}{ Temperature $\left({ }^{\circ} \mathrm{C}\right)$} \\
\hline & & 10 & 15 & 20 & 25 & 30 \\
\hline \multirow{3}{*}{$\begin{array}{l}\text { Detached } \\
\text { larvae }\end{array}$} & $\mathrm{N}$ & 20 & 20 & 35 & 112 & 38 \\
\hline & $\begin{array}{l}\text { Premoulting } \\
\text { period } \\
(\text { days) }\end{array}$ & & & 24.1 t3.40 & $19.2 \mathrm{k} 3.19$ & $10.4 \pm 1.87$ \\
\hline & $\begin{array}{l}\text { Moulting } \\
\text { ratio(\%) }\end{array}$ & $\begin{array}{c}0 \\
(0)\end{array}$ & $\begin{array}{c}0 \\
(0)\end{array}$ & $\begin{array}{l}85.7 \\
(30)\end{array}$ & $\begin{array}{c}94.6 \\
(106)\end{array}$ & $\begin{array}{l}78.9 \\
(30)\end{array}$ \\
\hline \multirow{3}{*}{$\begin{array}{l}\text { Detached } \\
\text { nymphs }\end{array}$} & $\mathrm{N}$ & 5 & 5 & 6 & 5 & 5 \\
\hline & $\begin{array}{l}\text { Premoulting } \\
\text { period } \\
(\text { days) } *\end{array}$ & & & $71.2 \pm 3.11$ & $28.0 \pm 9.82$ & $17.0 \pm 4.32$ \\
\hline & $\begin{array}{l}\text { Moulting } \\
\text { ratio(\%)+ }\end{array}$ & $\begin{array}{c}0 \\
(0)\end{array}$ & $\begin{array}{c}0 \\
(0)\end{array}$ & $\begin{array}{c}83.3 \\
(5)\end{array}$ & $\begin{array}{l}100 \\
(5)\end{array}$ & $\begin{array}{c}80.0 \\
(4)\end{array}$ \\
\hline
\end{tabular}

A symbol of shows no moulting even after 3 months.

*Values are $\mathrm{M} \pm \mathrm{S}$. D.

'The numbers of ticks moulted are in parentheses.

\section{DISCUSSION}

The life history and effects of temperatures on development and growth in $H$. flava are discussed in comparison with those of H.longicomis.

\section{Life history of $H$. flava}

The genus Haemaphysalis exhibits the three-host life cycle ; the larva, nymph and adult each feeds once on its respective host during the life cycle, and subsequently the detached larva and nymph moult to the nymph and adult, respectively, and the engorged female, which mated on the host, oviposits on the ground after detachment. 
In the woodland, the abundance of $H$. flava larvae found during the summer with a great peak in August might be due to the newly hatched larvae from deposited eggs in spring. Such a larval unimodal activity has been reported also in Niigata Pref. (Saito, 1959), Chiba Pref. (Asanuma and Sakurai, 1958) and Saitama Pref. (Fujimoto et al., 1987). Most of these larvae appear to attach to hosts and to become the nymphs within the year. Although the larvae were not collected except for the period from August to October, they were collected from the Japanese hares captured near the study areas in winter. This implies that part of the larvae overwintered on hosts, as briefly described by Yoshida (1980) and Fujimoto et al. (1987). In the grassland, on the other hand, the absence of the larvae in summer seems to be attributed to an inhibiting influence of environmental factors (high temperature and low humidity) to which the eggs were exposed. In this connection, the egg development in $H$. flava is retarded by high temperatures (Fujimoto and Yamaguti, 1987b) and low humidities (Fujimoto, 1988), and all eggs did not hatch at $30^{\circ} \mathrm{C}$ (present study). Thus, the larval absence in the grassland during the summer might result from very high temperatures (over $30^{\circ} \mathrm{C}$ ) of the ground surface exposed to the sunlight and consequent low humidities.

The nymphal and adult $H$. flava are collected from vegetation throughout the year with declines in number in both summer and winter (Fujimoto et al., 1987). In both areas of the present study, a small number of nymphs and adults in both summer (July-September) and winter (February) might be due to the inhibitions for the tick activity, especially climbing up vegetation by high and low temperatures in summer and winter, respectively. In this connection, the larva, nymph and/or adult were collected on vegetation throughout the year with a small number of nymphs and adults in summer in the woodland, whereas no tick was collected in summer in the grassland ; therefore, it was revealed that grassland is a basically unsuitable environment for $H$. flava.

The seasonal fluctuation of $H$. flava populations on wild animals can not be discussed in detail because of a few host mammals captured only in winter (the hunting season). Since numerous ticks parasitised the Japanese hare during this season, the hare seems to be a most important host in winter for $H$. flava. Taking the above into consideration, the suggested life history of $H$. flava is schematically illustrated (Fig. 3).

As for H. longicornis, in spite of the presence of numerous ticks in both study areas, the absence of ticks during the period from November to February is closely related to hibernation under the ground, as pointed out also by some authors (Yoshida, 1975, 1980 ;Ito et al., 1983 ; Shiraishi et al., 1989 ). In both areas, the nymphs emerging from hibernation exhibited a conspicuous peak, but the larva and adult had no peak in spring : this might result from larval death during the hibernation period as shown also by Yoshida $(1975,1980)$ and from a small number of adults.

Judging from the distinct difference in winter activity between the two tick species, it was suggested that the temperature permitting activity for $H$. flava was lower than that for H. longicornis.

\section{Effects of temperatures on development and growth in $H$.flava}

Oviposition by the female, egg hatching, larval and nymphal moulting did not occur at the temperatures of $15^{\circ} \mathrm{C}$ and below. The developmental zero was $12.3^{\circ} \mathrm{C}$ and the critical low temperatures for larval and nymphal moulting were 14.5 and 


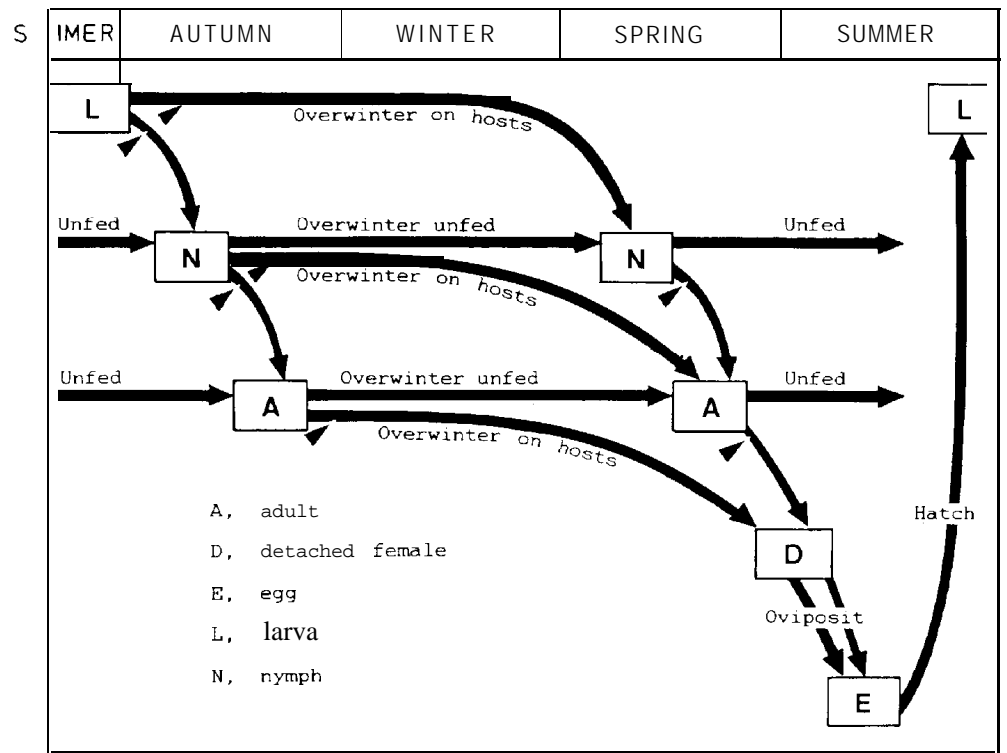

Fig. 3. Schematic diagram showing a suggested life history of Haemaphysalis flava in Kyushu. Arrow heads indicate ticks' attachment to hosts.

$17.0^{\circ} \mathrm{C}$, respectively. Regarding this, these values have been said to be $9.1,8.9$ and $13.3^{\circ} \mathrm{C}$ (Fujimoto and Yamaguti, 1987b), all of wich are considerably lower than our values. Such disparities with regard to the results between the above two studies might be brought about by the geographic variation. On the other hand, the developmental zero for $H$. longicornis (bisexual race) has been said to be $10.7^{\circ} \mathrm{C}$ (Shiraishi et al.,1982), $12.2^{\circ} \mathrm{C}$ (Yano et al., 1987) and $10.0^{\circ} \mathrm{C}$ (Fujimoto and Yamaguti, 1987b), and the critical low temperature for moulting has been described to be $10.2^{\circ} \mathrm{C}$ (Yano et al., 1987 ) and $8.6^{\circ} \mathrm{C}$ (Fujimoto and Yamaguti, 1987b) in larvae, and $11.8^{\circ} \mathrm{C}$ (Yano et al., 1987) and ca. $10^{\circ} \mathrm{C}$ (Fujimoto and Yamaguti, 1987b) in nymphs, all of which are lower than those for $H$. flava in this study.

The egg productivity at $25^{\circ} \mathrm{C}$ and $30^{\circ} \mathrm{C}$ was inferior to that at $20^{\circ} \mathrm{C}$, and no hatching occurred at $30^{\circ} \mathrm{C}$ in $\mathrm{H}$. flava. Such a harmful influence of high temperatures to oviposition and hatching agrees with the result of Fujimoto and Yamaguti (1987b). In contrast to $H$. flava, $H$. longicornis oviposits normally and the eggs hatch in a very high ratio at $30^{\circ} \mathrm{C}$ (Yano et al., 1987 ; Fujimoto and Yamaguti, 1987b) with a low hatchability $(39.8 \%)$ even at $35^{\circ} \mathrm{C}$ (Heath, 1979).

Thus, it was revealed that the lowest temperature for normal development and growth in $H$. flava is higher than in $H$. longicornis, and the highest temperature in the former is lower than in the latter ; that is, it was suggested that $H$. flava develops and grows within a narrower range of temperatures than does $H$. longicornis.

The conclusion reached can be expressed as follows ; $H$. flava can be active even in the season at relatively low temperatures, but the development and growth is considerably restricted by both high and low temperatures. In contrast with this, $H$. 
longicornis can develop in the broad range of temperatures. Such a disparity between the two species appears responsible for the scarcity of H. flava, i. e. the dominance of H. longicornis in pastures.

\section{ACKNOWLEDGEMENTS}

We thank Dr. K. Okano, Kyushu University Farm for facilities in collecting ticks, Mr. Y. Inoue for hunting hares and Professor E. W. Jameson, Jr., University of California for comments on the manuscript. This work was supported in part by a Grant-inAid from the Ministry of Education, Science and Culture, Japan.

\section{REFERENCES}

Asanuma, K. and N. Sakurai 1958 On the seasonal occurrence of the tick, Haemaphysalis flava, on wild hares (Lepus timidus brachyums) in the endemic area of Yato-byo or tularemia in Chiba Prefecture, Japan (a preliminary note). Misc. Rep. Res. Inst. Natur. Resources, 48 : 28-39 (in Japanese with English summary)

Asanuma, K., S. Ohara, N. Sakurai, H. Nakagawa, A. Goto and T. Sato 1956 Studies on ticks infesting source animals of Yato-byo or tularemia in Japan. Jpn.J. Sanit. Zool., 7: 127 (in Japanese)

Chikaki, H. 1976 Biological studies on Haemaphysalis longicornis. Spec. Rep. Insect Management Lab., Fac.Agr., Shimane Univ., (1) : 1-76 (in Japanese with English summary)

Fujimoto, K. 1988 Ecological studies on ixodid ticks. 5. The effect of humidity on the oviposition and development of Haemaphysalis longicomis and H. flava (Acarina : Ixodidae). Jpn. J. Sanit. Zool., $39: 27-33$ (in Japanese with English summary)

Fujimoto, K. and N. Yamaguti 1987a Ecological studies on ixodid ticks. 3. The distribution of ixodid ticks within a low mountain zone in the south-western part of Saitama Prefecture. Jpn. J. Sanit. Zool., 38 : 13-18 (in Japanese with English summary)

Fujimoto, K. and N. Yamaguti $1987 \mathrm{~b}$ Ecological studies on ixodid ticks. 4. The effect of temperature on the oviposition and development of Haemaphysalis longicornis and H. flava (Acarina : Ixodidae). Jpn.J. Sanit. Zoot., 38: 225-232 (in Japanese with English summary)

Fujimoto, K., N. Yamaguti and M. Takahashi 1986 Ecological studies on ixodid ticks. 1. Ixodid ticks on vegetations and wild animals at low mountain zone lying south-western part of Saitama Prefecture. Jpn. J. Sanit. Zool., $37: 325^{-331}$ (in Japanese with English summary)

Fujimoto, K., N. Yamaguti and M. Takahashi 1987 Ecological studies on ixodid ticks. 2. Comparison of the seasonal occurrence of three ixodid ticks, Haemaphysalis flava, Ixodes ovatus and $I$. nipponensis in the south-western part of Saitama Prefecture. Jpn. J. Sanit. Zool., 38:7-12 (in Japanese with English summary)

Fujita, H., H. Ootake and S. Ohara 1985 Isolation of Francisella tularensis from a tick Haemaphysalis flava parasitized on a dead hare and serologic survey on range cattle in Kawatabi Farm, Miyagi Prefecture, Japan. Jpn.J. Sanit.Zool., 36 : 75-77 (in Japanese with English summary)

Hashimoto, Y., T. Mizumoto, N. Ohkuma and K. Miyamoto 1989 A case of Lyme disease. Jpn. J. Clin. Dermatol., $43: 1097-1100$.

Heath, A. C. G. 1979 The temperature and humidity preferences of Haemaphysalis longicornis, Ixodes holocyclus and Rhipicephalus sanguineus (Ixodidae) : Studies on eggs. Int. J.Parasitol., 9: 33-39

Honma, K. 1989 A case of Lyme disease and a case of erythema chronicum migrans. Jpn. J. Clin. Dermatol., $43: 1105 \sim 1108$ (in Japanese)

Ito, Y., N. Watanabe and T. Matsumura 1983 Overwintering of Haemaphysalis longicornis (Acari: 
Ixodidae) at a pasture, Nasu Plateau, Japan. Bull. Natl.Grassl. Res. Inst., 24 : 110-118 (in Japanese with English summary)

Kakuda, H., S. Shiraishi and T. A. Uchida 1989 Ticks from wild mammals in the Kyushu district including Okinawa Prefecture, Japan. J.Fac.Agr., Kyushu Univ., 33 : 267-273

Kawabata, M., S. Baba, K. Iguchi, N. Yamaguti and H. Russell 1987 Lyme disease in Japan and its possible incriminated tick vector, Ixodes persulcatus. J. Infect. Dis., $156: 854$

Mahara, F. 1987 Japanese spotted fever. A new disease named for spotted fever group rickettsiosis in Japan. Ann. Rep. Ohara Hosp., 30: 83-91 (in Japanese with English summary)

Mahara, F. and H. Fujita 1989 Japanese spotted fever : clinical features and vectors. The Saishin-Igaku, 44 : 915-919 (in Japanese with English summary)

Miyamoto, K., K. Takahashi, N. Sato, K. Uraguchi, S. Matsuo, H. Iizuka, M. Mori, Y. Tsuboi and K. Ohtsuka 1990 Cases of erythema and Lyme disease associated with tick bite in Hokkaido, Japan. Jpn. J. Sanit. Zool., $41: 63-65$

Namba, N. 1958 Ecological studies on Haemaphysalis bispinosa, a harmful tick in the pasture of northern Japan. Hokkaido Natl. Agr.Exp.Stn.Rep., (50) :1-99 (in Japanese with English résumé)

Saito, Y. 1959 Studies on ixodid ticks. Part I. On ecology, with reference to distribution and seasonal occurrence of ixodid ticks in Niigata Prefecture, Japan. Acta Med. Biol., 7: 193-209

Shiraishi, S., T. Mōri, K. Funakoshi, S. Arai, N. Kawaji, M. Nishimura and T. A. Uchida 1982 Fundamental studies on the control of the cattle tick, Haevnaphysalis longicornis, at Kujū Highland. I. Preliminary report on the ecology of the tick. Sci. Bull. Fac.Agr., Kyushu Univ., 36 :101-114 (in Japanese with English summary)

Shiraishi, S., K. Yoshino and T. A. Uchida 1989 Studies on seasonal fluctuations of populations and overwintering in the cattle tick, Haemaphysalis longicornis. J.Fac.Agr., Kyushu Univ., 34:43-52

Takada, N., H. Fujita, F. Mahara, T. Tada and W. H. Huang 1988 Surveys of natural cycle of spotted fever pathogens in Japan. Proc.Sino-Jpn.Symp. Parasitic Zoonoses: 185-192

Yamaguti, N., V. J. Tipton, H. L. Keegan and T. Toshioka 1971 Ticks of Japan, Korea and the Ryukyu Islands. Brigham Young Univ. Sci. Bull. Biol. Ser., 15 :1-226

Yano, Y., S. Shiraishi and T. A. Uchida 1987 Effects of temperature on development and growth in the tick, Haemaphysalis longicornis. Exp.Appl.Acarol., 3: 73-78

Yoshida, T. 1975 Ecological studies for the control of the tick in the pasture. J.Fac. Liberal Arts, Shinshu Univ., $9: 27-111$ (in Japanese with English summary)

Yoshida, T. 1980 Ecology of the tick, Haemaphysalis longicornis, in the pasture of Japan. Biological Science, 32: 1-10 (in Japanese) 